\title{
Load Balancing in Cloud Computing using Modified Throtled Algorithm
}

\author{
Nagadevi.S, Uma Maheswara Reddy.P, Rama Krishna Reddy.V
}

\begin{abstract}
In the coming age of computing world, cloud computing plays an important role. Cloud computing gives assets to customer on interest. The assets might be programming assets or equipment assets. Cloud computing structures are circulated, parallel and serve the requirements of various customers in various situations. This appropriated design conveys assets cloud to convey benefits productively to clients in various topographical channels. Customers in a circulated domain produce ask for haphazardly in any processor. So the real downside of this haphazardness is related with errand task. The unequal undertaking task to the processor makes imbalance i.e., a portion in the processors work a lot and some of them stay idle. To exchange the load from over-burden procedure to under stacked procedure straightforwardly is the goal of load balancing. Out of many issues involving in distributed computing, load balancing is one of the focal issue. To accomplish superior, least reaction time and high asset use proportion we have to exchange the assignments between hubs in cloud arrange. Load balancing strategy is utilized to appropriate errands from over stacked hubs to under stacked or inert hubs. In following areas we talk about cloud computing, load balancing strategies.
\end{abstract}

Keywords : Load balancing,CloudComputing, Virtual machine, CloudAnalyst.

\section{INTRODUCTION}

As of late Cloud Computing has turned out to be one of the well known methods embraced by both industry and the scholarly world giving a adaptable and productive approach to store and recover the information documents. Be that as it may, the primary issue is to plan the approaching solicitations productively with extremely low reaction time. Numerous algorithms like Throtled, Round Robin, Stochastic Hill Climb and so on are broadly utilized for executing the customer's demand with a negligible reaction time [1]. Be that as it may, limitations, for example, heterogeneity, dependability and high correspondence defers should be tended to while structuring effective scheduling algorithms. In general, there are two types of algrithms in load balancing, namely static and dynamic algrithms. Static algorithms are commonly reasonable for correlative and stable condition still they emit poor outcomes at whatever point qualities are powerfully evolving. Besides the dynamic algorithms are increasingly adaptable and like manner take distinctive kinds of structure properties (both earlier and amid the run-time) into record. Cloud computing framework contains servers, virtual machines, server farms, storage devices and so on

which are interconnected in a proficient way. Nowadays, figuring frameworks vivaciously rely upon Virtualization advancement and henceforth makes the servers functional with the expectation of complimentary applications. Also, power proficiency of the datacentres is also improved by virtualization process and along these lines enabling the asignment of different virtual machines (VMs) to alone physicl server [2]. In this way, the server can be shutted down over a segment in the distributed computing framework (rest state) moreover, acknowledging less power utilization.

\section{NEED OF LOAD BALANCING IN CLOUD}

A webpage or a web-application can be gotten to by various clients anytime. It is especially troublesome to control all the client requests by a web application at a time. All over it might result in framework breakdowns. Here, it expect an essential job. Load balancing is a route that is separating the work that a PC needs to perform between at least two PCs with the end goal that the work is performed quicker and gives productive use of assets. It spreads the heap to such a degree, that no PC is seriously stacked while particular PCs are doing small amount of task or they stay inactive. Load balancing enables that every one in the hubs of the system will perform around equivalent proportion of work. The fundamental destinations of the cloud is to upgrade reaction time, lessen cost, and give improvement in execution; so the Cloud is additionally known as a pool of administrations [1]. Load not only implies the site traffic that has different sorts like the memory limit issue, CPU load, network load, etc but it also regards to distributed computing. It is the task to disseminate the virtual machines load over all hubs (end client gadgets) to boost the resources use and to give maximum fulfillment to clients. Because of sharing load, every centre point can perform capably; receiving and sending data can be done right away. Among customer and server, a load balancer is a gadget that acknowledges errands from various customers and then it disperses the undertaking to something like a server choose any one of the algorithms 


\section{Necessity of Balancing Load in Cloud}

The principle grouping of load balancing is to spread the load progressively between the hubs. Most extraordinary utilization of resource and high customer satisfaction extent can be achieved by this. A perfect load balancing algorithm help to make utilization of the accessible assets most proficiently, by guaranteeing no hub is

over stacked or under stacked.Objectives of load balancing include [3]:

- Optimized resource utlization

- High throughput

- Improved response time

- Avoiding overload

\section{RELATED WORK}

Various procedures are available [1],[3],[4],[5] to modify the load in cloud as shown in this paper. The algorithms are separated in to two kinds dependent on the present framework state and dependent on who started the procedure. These algrithms are described under three sorts subject to the initiator of the methodology as the Sender ,Receiver and Symmetric initiated.

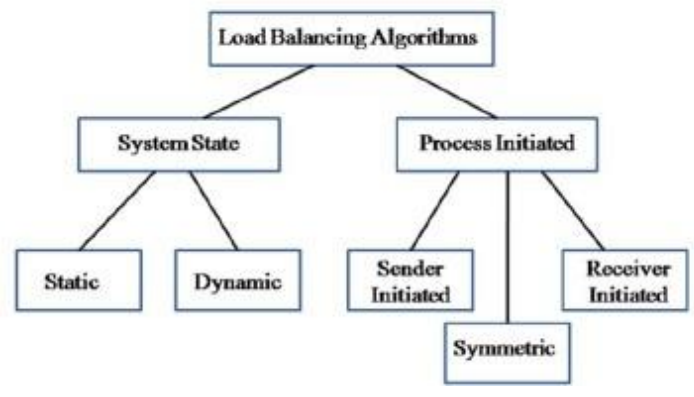

Fig1.Classification of load balancing algorithms

\section{Static Algorithms}

This requires the earlier information regarding the framework like memory and execution. These calculations don't depend on data with respect to the present condition of the node. In static algorithm, choice on adjusting the load is taken at accumulate time. Every one of the hubs including properties are known ahead of time, it is past data work dependent.The static algorithm do not use the framework data while disseminating the data and is less mind boggling. With low kind of variety, these algorithms works appropriately in a framework load.

1. Round robin [6]: Here managing time framework will be implemented to get the process information. The time is partitioned into cuts here and certain period between time will be given to the each centre point, where these centres needs to play out the task. If the getting ready isn't done inside the time quantum, it needs to sit tight for accompanying space.

2. Min-Min [2]: Here, firstly the base fruition time of the considerable number of hubs is determined. An undertaking with least culmination time is chosen and alloted to the comparing hub. This procedure is rehashed until every one of the undertakings are doled out to the hubs.

3. Max-Min [2]: It chips away at the contrary procedure contrasted with min-min where an undertaking with most extreme fulfillment time is seen as first. In this algorithm first the normal consummation time of the considered number of assignments is determined and an errand is picked which is requiring most extreme time for fulfillment.

4. OLBA [4]: The execution time and the present heap of the hub were not figured out in this algorithm. The assignments were randomly given to the hubs. The errand getting ready takes more time since the execution time wasn't figured out in the hub.

\section{Dynamic Algorithms}

Here choices are made dependent on the present condition of framework for example it won't think about the earlier learning about the framework. It consists distinctive arrangements like exchange approach, choice strategy, area approach and data arrangement to adjust the load. It similarly considers the alterations in the hub effectively. At whatever point, if a centre is known to having significant burden on it, then it will be given to a centre point that has less burden.

a. Ant Colony enhancement strategy [2]: Here the calculation relies upon the possibility of ants which structure a framework searching for sustenance. Here, an insect starts moving forward one after one reaching the centre points and checks whether a centre point is over- loaded or under stacked and then data is stored. If an over-loaded centre point was found by the insect, then backward improvement starts and data will be shared to the previous under stacked centre. b. Honey bee Forging Algorithm [3]: This is also known as a decntralized method that exists in nature. An organized subject to the direct of honey bees. The load in this algorithm adjusts the crosswise over heterogeneous hubs of the cloud. The starting load in the hubs is determined and then it check if the hub is adjusted, over stacked or under stacked. From stacked centre an endeavor is either removed or considered based on its need. And if needed, it is to the designated to a carefully stacked centre point.

c. Biased Random Sampling Algorithm [4]: Every one of the servers in the cloud are known as hubs. The system in here is treated as an virtual outline. The hub can be accessed by the free assets when addressed by the in-degree. Based on in-degree the heap balancer appoints the assignments to the hub. Right when an errand is doled out, there will be decrementation in the in-degree and it results in enlargement while executing the movement.

d. Active Clustering algorithm [5]:This algorithm was an improved variation of subjective investigating. Grouping idea is used here. The major rule in here is assembling near centre points and working subject to the collected centres.. A hub that begins the methodology and picks another strategy is known as a go between hub. 
A go between hub associates an underlying hub to the near by and then it gets detached. This technique is carried on iteratively to alter the load.

Table1.Inference from the survey

\begin{tabular}{|c|c|c|c|}
\hline $\begin{array}{l}\text { Load } \\
\text { Balancing } \\
\text { Algorithm }\end{array}$ & $\begin{array}{l}\text { Static/ } \\
\text { Dynami c }\end{array}$ & Merits & Demerits \\
\hline $\begin{array}{l}\text { Round } \\
\text { Robin }\end{array}$ & Static & $\begin{array}{l}\text { Short tasks with } \\
\text { fixed time has good } \\
\text { performance }\end{array}$ & $\begin{array}{l}\text { More } \\
\text { completi on } \\
\text { time for } \\
\text { large tasks }\end{array}$ \\
\hline Max-Min & Static & $\begin{array}{l}\text { Better response } \\
\text { based on the } \\
\text { requirements } \\
\text { if known prior }\end{array}$ & $\begin{array}{l}\text { Takes long } \\
\text { time for task } \\
\text { completi on }\end{array}$ \\
\hline Min-Min & Static & $\begin{array}{l}\text { Small tasks } \\
\text { have best } \\
\text { results with } \\
\text { small time. }\end{array}$ & Starvatio $\mathrm{n}$ \\
\hline $\begin{array}{l}\text { Opportunist ic } \\
\text { Load } \\
\text { Balancing }\end{array}$ & Dynami c & $\begin{array}{l}\text { Improved } \\
\text { performance } \\
\text { Resource } \\
\text { utilization }\end{array}$ & $\begin{array}{l}\text { Takes } \\
\text { more } \\
\text { time } \\
\text { for task } \\
\text { completi on }\end{array}$ \\
\hline $\begin{array}{l}\text { Ant Colony } \\
\text { Optimizatio n }\end{array}$ & Dynami c & $\begin{array}{l}\text { Computational } \\
\text { ly fast Minimizes } \\
\text { makespan }\end{array}$ & $\begin{array}{l}\text { Search } \\
\text { takes } \\
\text { long } \\
\text { time } \\
\text { Comple } \\
\mathrm{x}\end{array}$ \\
\hline $\begin{array}{l}\text { Honey Bee } \\
\text { Foraging }\end{array}$ & Dynami c & $\begin{array}{l}\text { Reduced } \\
\text { response time } \\
\text { Increases } \\
\text { throughput }\end{array}$ & $\begin{array}{l}\text { More } \\
\text { time is } \\
\text { taken by } \\
\text { low } \\
\text { priority } \\
\text { loads }\end{array}$ \\
\hline $\begin{array}{l}\text { Biased } \\
\text { Random } \\
\text { Sampling }\end{array}$ & Dynami c & $\begin{array}{l}\text { Improved } \\
\text { performance } \\
\text { Improved } \\
\text { resource } \\
\text { utilization }\end{array}$ & $\begin{array}{l}\text { Respons } \\
\text { e time is } \\
\text { More }\end{array}$ \\
\hline $\begin{array}{l}\text { Active } \\
\text { clustering }\end{array}$ & Dynami c & $\begin{array}{l}\text { Similar nodes are } \\
\text { grouped } \\
\text { togater }\end{array}$ & $\begin{array}{l}\text { Differen } \\
\mathrm{t} \text { type of } \\
\text { nodes } \\
\text { makes } \\
\text { algorith } \\
\mathrm{m} \text { less } \\
\text { responsi } \\
\mathrm{ve}\end{array}$ \\
\hline
\end{tabular}

Step 1: Load Balancer initially pocess an index table with VMs of availability status ' 0 '.

2 : Data Centre Controller will receive a new request. load balancer.

Step 4: VM ID is detected by TLB algorithm form the available index table.

- Request is sent to particular VM by that ID from Data Centre Controller.

- Throtled Load Balancer is informed for new allocation by Data Centre Controller.

- This VM is updated to busy stauts ' 1 ' and In case, if no VMs available(empty "available index":

- Value of -1 is returned by TLB algorithm to Data Centre Controller.

- Request is arranged by the Data Centre Controller.

Step 5: Data Centre Controller receives a response when the process is done in VM and notifies that TLB is stopped.

Step 6: Based on the number of requests step3 is replicated till the index table becomes empty.

Response time is optimized more than the default RR algorithm However, the confinement is to recognize the VM is readied'0' with the list size out.

\section{PROPOSED ALGORITHM (MTA)}

\section{Sequence flow of steps:}

Step 1: The MTA maintains and updates the process in two different indexed tables.

- Available Index: Available status of VMs will be '0'

- Busy Index: Non available status of VMs will be '1'.

Since it is initial stage all VMs are stated as available in index and busy index is empty.

Step 2: Data Centre Controller will receive a new request.

Step 3: Query for VM is done by the data centre to throtled load balancer.

Step 4: VM ID is detected by TMA algorithm form the available index table.

- Request if sent to particular VM by that ID from Data Centre Controller.

- MTA is informed for new allocation by Data Centre Controller.

-This VM is updated to busy index table and then the Data Centre Controller will wait for new request.

If all the VMs are unavailable i.e available index becomes empty

- Value of-1 is returned by MTA algorithm to Data Centre Controller.

- Request is arranged by the Data Centre Controller.

Step 5: VM sends the response to the Data Centre Controller after processing and the "available index" is 
updated.

Step 6: On the off chance that there are increasingly number of requests, the Data Centre Controller goes over Step 3 and the technique is repeated until the "Accessible Index" table becomes empty. With the presented algorithm (MTA), it is possible to recognize the VM accessible (status'0') with the span of the table "Available Index" is more versatile than the Throtled Algorithm. This enhance the execution of the system.

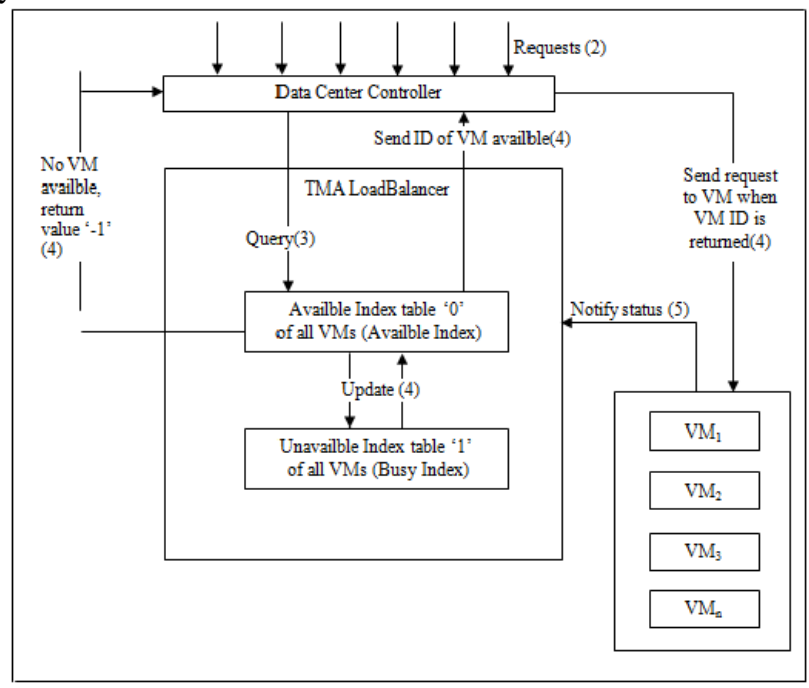

Fig2.TMA Operation Diagram

\section{SIMULATION \& RESULTS}

Cloud Analyst toolkit is used to simulate and examine the presented algorithm with two existing algorithms:

Round_Robin and Throtled.Processing time of the data centre and Overall response time of the cloud are the main parameters considered in this paper.

\section{SETUP \& CONFIGURATIONS}

Corresponding to five zones with a specific time 5 userbases are simulated with specific time zone and average peak hours foe each zone are defined also the number of requests for each userbase are specified

\begin{tabular}{|l|l|l|l|}
\hline Base & Region & $\begin{array}{l}\text { Requests per } \\
\text { hour }\end{array}$ & $\begin{array}{l}\text { Request } \\
\text { size } \\
\text { (in bytes })\end{array}$ \\
\hline UB1 & 0 & 100 & 100 \\
\hline UB2 & 1 & 150 & 100 \\
\hline UB3 & 2 & 200 & 100 \\
\hline UB3 & 3 & 250 & 100 \\
\hline UB4 & 4 & 300 & 100 \\
\hline
\end{tabular}

Table2.User Base Configurations.

\begin{tabular}{|l|l|l|l|}
\hline Base & $\begin{array}{l}\text { Peak } \\
\text { hours } \\
\text { (GMT) }\end{array}$ & $\begin{array}{l}\text { Users in } \\
\text { peak hours }\end{array}$ & $\begin{array}{l}\text { Users in } \\
\text { non peak } \\
\text { hors }\end{array}$ \\
\hline UB1 & $1-3$ & 10000 & 100 \\
\hline UB2 & $4-7$ & 10000 & 100 \\
\hline UB3 & $8-11$ & 10000 & 100 \\
\hline
\end{tabular}

\begin{tabular}{|l|l|l|l|}
\hline UB4 & $12-15$ & 10000 & 100 \\
\hline
\end{tabular}

Table3.Peak hours \& users

Data Center Configuration Can be also specified with required band widths for each centre.Here used band widths are defaults that are included in tool. No change in VM configurations except the count of VMs processing in each data centre. This simulation process is done for $20 \mathrm{VM}$ 's

\section{RESULTS}

As of the Round Robin framework,solicitations are passed on consistently above the VMs so that there will be no prerequisite for the queues to be scattered. Concerning the Throtled system, the location of VMs in the state index table by the revelation procedure from the beginning stage of the table beyond what many would consider possible of the table will incite the status of solicitations to line when the structure has the amount of VMs extensive. In TMA, it used of two status list table (Available and Busy Index), the structure simply need to circulate solicitations to virtual machines in the Available record table without searching for them. This wipes out the necessity to arrange the framework, upgrading the handling time of DC.

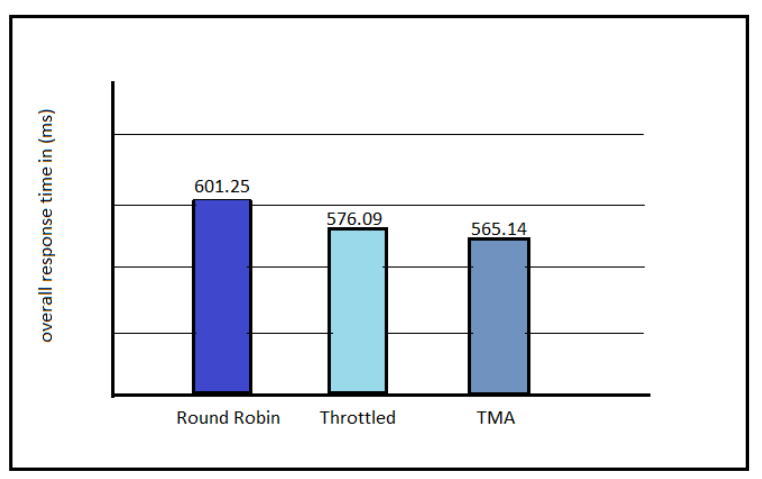

Figure3.Response time analysis

From exploratory outcomes elevated in the above case,It make us to have a glance that with the MTA algorithm, the count of solicitations that need to queue has diminished and the reaction time of the framework is improved compared to the other two existing algorithms. This implies the TMA algorithm does finer load balancing over the Throtled and Round Robin algorithms.

\section{CONClusion}

This paper revolves around the conspicuous load balancing algorithms in the present cloud circumstances, looking at and proposing an modified algorithm (TMA) in light of algorithm starting at now set up to improve load balancing over increasingly settled algorithms, and has met the going with target. The outcomes got from the presented algorithms have accomplished the goal improving response time of hubs cloud appeared differently in relation to two existing algorithms. This furthermore suggests with the presented algorithm, the execution of cloud is enhancingly stood out from the two algorithms Round Robin and 
Throtled. Our presented count has shown better productivity with the amount of VMs increases: diminishing the response time and dealing with time of cloud servers. Later on, we will consider moves up to propel the execution of the calculation.Further work should be conceivable by examining new productive algorithms which can care for better equalization among parameters.

\section{REFERENCES}

1) "Cloud task scheduling basedon load balancing ant colony optimization,"by K. Li, G. Xu, G. Zhao, Y. Dong, and D. Wang, Sixth Annu. Chinagrid Conf, pp. 3-9, Aug. 2011.

2) "Load Balancing of Nodes in Cloud Using AntColony Optimization". In proc. 14th International Conference on Computer Modeling and Simulation (UKSim), IEEE, pp:3-8, March

3) “Load Balancing The Essential Factor In Cloud Computing”, by Mr. Jayant Adhikari, Prof. Sulabha Patil, International Journal of Engineering Research \& Technology (IJERT), Vol. 1 Issue. 10, pp. $1-5$,

4) "Efficient and Enhanced Algorithm in Cloud Computing" International Journal of Soft Computing and Engineering (IJSCE)ISSN:2231-2307, Volume-3, Issue-1, Mfarch 2013.

5) "Dynamic load balancing: improve efficiency in cloud computing,"by A.Roy International Journalof Emerging Research in Management \&Technology, vol. 9359, no. 4,pp. 78-82, 2013.

6) “Load balancing in cloud computing,"by R. Kaur and P. Luthra, Int. Conf. 2007. on Recent Trends in Information, Telecommunication and Computing, ITC, pp. 1-8, 2014

7) "Load Balancing Algorithms in Cloud Computing: A Survey of Modern Techniques"by Sidra Aslam Munam, Ali Shah 2015 National Software Engineering Conference (NSEC2015),IEEE, pp:30-35

8) "Static Load Balancing Algorithms In Cloud Computing:Challenges \& Solutions" International Journal Of Scientific \& Technology Research Volume 4, Issue 10, October 2015

9) “A Comparative Study of Different Static and Dynamic Load Balancing Algorithm in Cloud Computing with Special Emphasis on Time Factor",by Abhijit Aditya, Uddalak Chatterjee and Snehasis Gupta, International Journal of Current Engineering and Technology, Vol.5, No.3 (June 2015) . 